Trans/Form/Ação, São Paulo

9/10: 41-49, 1986/87.

\title{
O ENSAIO DE ADORNO E A PRODUÇÃO SOCIAL DA FORMA
}

Iná Camargo COSTA*

RESUMO: Com o objetivo de participar num debate em torno da forma ensaio em sua relação com a filosofia, discutimos essa opção formal da Escola de Frankfurt a partir do texto de Adorno "O ensaio como forma". Uma vez encontrada sua proposição de que o objeto do ensaio é um conflito detido, tentamos sugerir algumas das razões sociais que induzem essa escolha.

UNITERMOS: Marxismo clássico; marxismo ocidental; método dialético; dialética negativa; teoria crî́ica; intelligentsia; organização política.

“...intencionalmente, ele não fazia nada. Esperava (que alguma coisa acontecesse...)"

Robert Musil, L'homme sans qualités.

\section{ADVERTÊNCIAS}

1.1. As considerações que seguem a propósito do texto de Adorno "O ensaio como forma" (1, p. 12-36) só se tornaram possiveis graças ao privilégio que tivemos de consultar alguns dos escritos inéditos do Professor Paulo Eduardo Arantes, parte de uma exaustiva pesquisa sobre o processo histórico no qual germinou a dialética enquanto "espírito de contradição organizado", formulação sua que já vamos adotando (4, p. 37-70). Por outro lado, como sua pesquisa diz respeito às peripécias da vida intelectual na Alemanha de fins do século XVIII e início do século XIX, as eventuais impropriedades e precipitações na tentativa de examinar a retomada do problema do ensaio já em meados do século $X X$ correm evidentemente por nossa conta. $A$ mesma restrição vale para os mais prováveis curto-circuitos, incompreensões e outras debilidades.

1.2. A circunstância em que o texto foi originalmente elaborado explica o aspecto mais imediato do seu interesse: tratava-se de intervenção num debate em que, a partir do tema geral "Filosofia e literatura", estavam em pauta os ensaios de Sêneca. O elo de ligação entre Sêneca e Adorno só pode ser o ensaio e, já que em Adorno encontramos uma defesa empenhada da opção por essa forma, o caso era tentar repor a

* Departamento de Filosofia - Faculdade de Educação, Filosofia, Ciências Sociais e da Documentação - UNESP - 17500 - Marília - SP. 
forma ensaio como problema (e também exercitar o espírito de contradição - para não dizer espírito-de-porco - posto que em situação de debate). Motivos de força maior, entretanto, obrigaram, meio a toque de caixa, uma reformulação radical de planos e aquilo que não passava de um arrazoado em torno dessa família de ensaístas iniciada por Sêneca teve que se transformar numa palestra independente e sem a prévia exposição sobre o velho filósofo. O resultado dessas aventuras é o texto que segue.

\section{O ESPÍRITO DE CONTRADIÇÃO REDESORGANIZADO}

No já referido texto da revista Manuscrito, Paulo Arantes mostra algumas das razões que levaram Hegel à tentativa de "organizar o espírito de contradição", trabalho que resultou no tão detratado quanto pouco conhecido método dialético. Como explica o Paulo, "espírito de contradição" era o traço mais típico da intelectualidade contemporânea de Hegel, aparecendo também sob a forma do nihilismo, da dialética negativa, entre outras. Para Hegel, tratava-se de "pôr nos trilhos" o "espírito de contradição", ou seja, organizálo, dar-lhe método. Dai o filósofo ter definido para Goethe a dialética como espírito de contradição organizado (4, p. 37).

Quem conhece um pouco da história da descendência hegeliana sabe no que deu a principal tentativa de pôr em prática o "espírito de contradição organizado". Trata-se, evidentemente, do marxismo, que tem entre seus créditos (ou débitos, depende do ponto de vista) a direção do mais importante acontecimento histórico do século $X X$, a revolução de outubro de 1917. No período que vem de Hegel à Revolução de Outubro boa parte (para não dizer a melhor) da intelectualidade européia foi atraída pelo "espírito de contradição organizado" e alguns, a começar por Marx e Engels, levaram-no às últimas conseqüências, isto é, tornaram-se militantes do movimento operário.

Mas a Revolução de Outubro, em seus desdobramentos, vai participar significativamente de uma nova situação na qual o espírito de contradição volta a se desorganizar, mas sem que se possa sequer cogitar de uma reedição do contexto histórico dos tempos de Hegel. O que não impede o reaparecimento de mais de uma das facetas daquele antepassado. E dentre as novas, a principal vem a ser primeiro o abandono e depois a crítica da organização: após as catástrofes que o movimento operário sofreu desde a década de vinte, progressivamente intelectuais marxistas deixam de ser militantes de partidos operários, sem entretanto deixarem de ser marxistas e adeptos da dialética. $\mathrm{O}$ marxismo ocidental e uma de suas vertentes, a Escola de Frankfurt, são exemplos da produção filosófi-

ca indissoluvelmente vinculada a esse contexto. É essa a explicação de Perry Anderson para o fenômeno: "nascido do malogro das revoluções proletárias nas zonas desenvolvidas do capitalismo europeu após a Primeira Guerra Mundial, ele desenvolveu-se no meio de uma crescente cisão entre a teoria socialista e a prática da classe operária (...) Em conseqüência disso, os teóricos refugiaram-se nas universidades, afastando-se da vida do proletariado dos seus próprios países, e a teoria abandonou a economia e a política pela filosofia" (3, p. 120-121). Em outra formulação que resume um pouco o pensamento de Perry Anderson, o marxismo ocidental, enquanto expressão mais interessante do espírito de contradição redesorganizado, se caracteriza pelo rompimento dos laços que ligaram o marxismo clássico ao movimento operário e a esse rompimento corresponde uma alteração do foco intelectual do marxismo: enquanto Marx sai da filosofia em direção à economia política, os marxistas ocidentais voltam para a filosofia. Isto implica uma outra característica, agora relativa ao discurso, que põe o marxismo ocidental em novo contraste com o clássico: enquanto neste o local do discurso é o sindicato ou o partido, naquele é o centro de pesquisa ou o departamento universitário; o discurso filosófico,

Trans/Form/Ação, São Paulo, 9/10: 41-49, 1986/87. 
acompanhado de suas dificuldades técnicas progressivamente proibitivas, por se desenvolver numa linguagem altamente especializada, substitui o discurso de intervenção política.

Quanto às facetas reintroduzidas pela redesorganização do espírito de contradição, enumeremos apenas algumas das que Perry Anderson desenvolve: pessimismo generalizado, ecletismo teórico (tentativas de combinar o marxismo com outros sistemas intelectuais, como os de Max Weber, Husserl/Heidegger, Freud, Nietzsche, Bachelard, etc.), preocupação essencial com a cultura burguesa, tanto como fonte de informação quanto como objeto de crítica e, pelo menos no nivel das intenções, postura de não-capitulação ao status quo.

\section{O ENSAIO COMO FORMA, DE ADORNO}

Dentre os países que "sobreviveram" à Segunda Guerra Mundial, certamente a Alemanha Ocidental conheceu a história mais singular: berço da dialética moderna, do marxismo e do maior partido operário até então conhecido, o preço que pagou (e paga) pela sobrevida do capitalismo (com direito à presença permanente das forças armadas angloamericanas) inclui a manutenção da ordem social mais reacionária do mundo dito livre. Não resistimos à tentação de transcrever a passagem de Perry Anderson a seu respeito: "A Alemanha Ocidental do pós-guerra era agora, social e politicamente, o mais reacionário dos países capitalistas da Europa Ocidental; a sua tradição marxista fora extirpada pelo chauvinismo nazi e pela repressão norte-americana e o seu proletariado encontrava-se de momento passivo e inativo (...) o Partido Comunista seria banido e o Partido Social Democrata abandonaria oficialmente qualquer conexão com o marxismo" (3, p. 48 -49). É nesse país e nesse contexto que a Escola de Adorno, o Instituto de Pesquisas Sociais de Frankfurt, onde se refugiou o pensamento marxista, conhece seu período de maior produtividade. O próprio texto que vamos apresentar é do período 1954-58. E é o conhecimento profundo dessa singularidade alemã que faz o nosso filósofo logo de início defender a forma do ensaio por razões explicitamente políticas (mas de política de intelectual, bem entendido): "Na Alemanha, o ensaio provoca a defesa porque recorda e exorta a liberdade de espírito, a qual, desde o fracasso de uma tíbia ilustração já fracassada nos tempos de Leibniz, não se desenvolveu suficientemente nem ainda hoje, sob as condições da liberdade formal, mas ao contrário sempre esteve disposta a proclamar como sua mais própria aspiração a submissão a quaisquer instâncias" (1, p. 12).

Ainda que seu pano de fundo seja a situação alemã esboçada, todos sabemos que as setas de Adorno têm um alvo bem preciso: a intelectualidade alemã apresentada como sempre disposta à submissão. Mas é possível precisar um pouco mais esse alvo, já que o próprio filósofo não se limita a fazer-lhe alusões tão vagas. Esse alvo mais preciso é apresentado como feroz inimigo do ensaio.

Para compreender ao menos superficialmente as razões do ataque de Adorno a essa facção da intelectualidade alemã, é necessária uma digressão mesmo que rápida: a sobrevida do capitalismo no pós-guerra teve conseqüências mais que desastrosas para a vida intelectual de um modo geral. Além da proletarização dos intelectuais (e, portanto, do fim radical de qualquer ilusão sobre liberdade), implicou a superfragmentação do saber. Ou, para usar a expressão corrente, levou a divisão do trabalho às últimas conseqüências. No capitalismo tardio, a palavra de ordem para a universidade é produzir especialistas - os profundos conhecedores de algum microcosmo do campo do saber que, entretanto, são necessariamente ignorantes de todos os demais. É o fenômeno que também foi chamado de idiotia dos peritos. A própria filosofia, campo que nos interessa, sucumbiu à tendência geral. Daí o peso e a importância política assumida no período por 
todas as correntes da filosofia analítica (e eis que acabamos nomeando o adversário de Adorno e do ensaio). Ernest Mandel, que resumimos acima, encerra com as seguintes palavras o seu capítulo sobre a ideologia no capitalismo tardio: "O verdadeiro ídolo do capitalismo tardio é o 'especialista' cego a todo o contexto global; o equivalente filosófico dessa especialização técnica é o neopositivismo" (9, p. 357).

Dada esta determinação maior da filosofia analítica, acompanhemos seus traços nos termos de Adorno: "só aceita como filosofia aquilo que se reveste da dignidade do universal, permanente e, se possível, originário, sem se ocupar da formação espiritual particular, a não ser na medida em que seja preciso exemplificar nela as categorias gerais, ou, pelo menos, na medida em que o particular se torna transparente através delas" (1, p. 12). Além de aceitar, mais que isso, aspirar à submissão, assume e luta pelo modelo da moral ilimitada do trabalho (aquela exigência de produtividade quantificável do trabalho intelectual, tão propalada por estas plagas ultimamante), tendo um medo pânico da negatividade e da interpretação que pretende ir além das aparências. Aliás, proíbe isso que considera "exercícios próprios de inteligências mal orientadas" e que levam à "invenção de fantasmas", pondo "interpretativamente conteúdos onde não há nenhum conteúdo a ser explicitado através de interpretação (1, p. 12-13). Ora, diz Adorno, "uma vez que se sucumbe ao terror dessa proibição de pensar além do que já se encontra pensado no dado, já se está aceitando a falsa intenção que homens e coisas abrigam de si mesmos" $(1$, p. 13).

O veto à interpretação se apóia num motivo de peso: trata-se de expulsar a "espontaneidade da fantasia subjetiva" em nome de um valor maior, a "disciplina objetiva"; devese, é claro, à "tendência positivista geral, que contrapõe rigidamente ao sujeito todo objeto possível como objeto de investigação e permanece, neste como em todos os seus momentos, na mera separação entre forma e conteúdo" (1, p. 13). A partir dessa radical separação entre forma e conteúdo, a tendência positivista pode também postular a exigência do método (daí o impulso à "neutra" disciplina da metodologia científica), seja ele obediente a Descartes ou à corrente empirista (pois, lembra Adorno, ainda que se apresentando sob a forma de ensaio, o empirismo, desde Bacon, sempre foi sobretudo método) e sua conseqüência necessária: a exigência de organização do pensamento em sistema ou, como insiste Adorno, a forma adequada para a exposição do pensamento filosófico, segundo a vitoriosa corrente analítica, seria o tratado.

Nada pode ser mais avesso a todas essas exigências do que o ensaio defendido por Adorno. Sua impertinência, como vimos, já começa no desagrádavel fato de exortar à liberdade de espírito e de recusar-se a admitir que prescrevam sua competência. Além do mais, "o esforço do ensaio ainda reflete o ócio infantil que se inflama sem escrúpulos com o que outros já fizeram (...) Não começa por Adão e Eva, mas por aquilo de que quer falar; diz o que lhe ocorre a seu respeito, termina quando ele mesmo se sente chegado ao final e não onde não falta mais nada a dizer" (1, p. 12). E tem mais: o ensaio não apenas não se submete à proibição de interpretar, mas ainda vai mais longe, pois suas interpretações não procuram fundamentos filológicos e são por princípio hiperinterpretações. Neste processo acaba retirando a máscara do que se apresenta como objetividade. O ensaísta sabe, além disso, que qualquer fenômeno espiritual (cultural) é sempre síntese de inúmeras significações objetivas, de modo que o receptor, para desvendá-las, precisa lançar mão da espontaneidade da fantasia subjetiva. Como se vê, trata-se de forma que deve mesmo ser combatida pelo "grêmio analítico".

Adorno não ignora entretanto que há ensaios e ensaios e, mais grave, que essas mesmas características, combinadas com algumas outras, permitem o cultivo do mau ensaio e este precisa ser criticado, embora por motivos diferentes dos analíticos. Um desses aspectos é o seu excessivo envolvimento com a organização cultural que prestigia os produtos do mercado, como nos casos lamentáveis de Sainte-Beuve e Stefan Zweig, ensaístas que participam do processo de mitificação das mercadorias culturais. Referindose especificamente a Stefan Zweig, diz Adorno: "Esta literatura não critica os conceitos

Trans/Form/Ação, São Paulo, 9/10: 41-49, 1986/87. 
abstratos fundamentais, os dados sem conceito, os clichês gastos, mas ao contrário os pressupõe implicitamente e, por isso mesmo, concorda completamente com eles" (1, p. 14-15). Para ele, Stefan Zweig abusa dos clichês psicologizantes, por exemplo, e por isso fornece bons argumentos para os inimigos da forma. Mas Adorno arremata: "Os maus ensaios não são menos conformistas que as más teses de doutoramento" (1, p. 15).

Descartado o mau ensaio, voltemos aos méritos dos bons. Desenvolvendo um de seus traços já indicados - põe em dúvida o direito absoluto do método - , Adorno destaca que o ensaio se recusa a reduzir tudo a um único princípio, acentua o parcial diante do total, é fragmentário. $E$, usando algumas moedas francesas que já circularam por aqui, podemos acrescentar por nossa própria conta: expõe uma compreensão prismática dos seus objetos, olha-os de esguelha, muda de planos, não tem nem procura um solo fixo. Mas voltando a Adorno, o ensaio se distingue por recolocar a ironia como forma de abordagem das coisas e de si mesmo e se insurge contra toda doutrina que declara indigno da filosofia qualquer objeto mutante ou efêmero: o ensaio pretende reparar uma velha injustiça, pois "não se deixa intimidar pelos ataques de uma degenerada e meditabunda profundidade que afirma a contraposição irreconciliável entre história e verdade" (1, p. 19). E porque toma experiência como referência à história, porque não aceita a distinção entre filosofia primeira e filosofia da cultura, porque não pretende buscar o eterno no efêmero, mas eternizar o efêmero, no ensaio o pensamento se liberta da idéia tradicional de verdade, suspendendo o conceito tradicional de método. Ainda neste capítulo encontra-se a razão por que é inerente à forma do ensaio a sua própria relativização: o ensaio se estrutura como se pudesse interromper-se a qualquer momento. Por isso também o ensaio pensa descontinuamente. Como a realidade é descontínua, o ensaio encontra a sua unidade através de rupturas, e não tentando encobri-las*. É bom lembrar, entretanto, que há uma outra razão, muito mais importante para Adorno, desse pensamento descontínuo: "a descontinuidade é essencial ao ensaio, seu objeto é sempre um conflito detido" (1, p. 27). Voltaremos a isto logo mais.

De um modo geral, mas não exaustivo, reunimos boa parte da artilharia empregada por Adorno contra o conjunto da filosofia analítica. Mas, como se sabe, esta constitui apenas seu principal adversário. A teoria crítica, também dialética negativa, tem outros, que vão sendo esgrimidos aqui e ali. Como é impossível reconstituir todos os seus entreveros, limitemo-nos ao debate com Lukács. Este filósofo quando jovem (1910) escrevera um ensaio com o significativo título "Sobre a essência e forma do ensaio" (8, p. 15-39) no qual, por razões que não cabe discutir aqui e de maneira algo tateante, propõe que se pense essa forma como gênero artístico. Uma outra proposição sua - que parece ter tido muito mais conseqüência - é a de que o ensaio aspira ao sistema. Aliás, esta idéia é apresentada, ainda que apoiada em informações problemáticas, segundo Cacciari $(5, \mathrm{p}$. 59-79), numa formulação ferocíssima: "O ensaísta é um Schopenhauer que escreve os Parerga à espera de seu (ou de outro) Mundo como vontade e representação; é um Batista que prega no deserto a vinda de alguém que há de vir, de alguém cujas sandálias ele não é digno de amarrar" (8, p. 37). Ou, em outra formulação do próprio Lukács, os ensaios estarão sempre antes do sistema. Seria o mesmo que dizer, interpretando em uma direção a metáfora do Batista, aspiram ao sistema, mas não têm condições de chegar a ele.

Essas as principais proposições que Adorno vai debater com Lukács. Como a questão do sistema já está devidamente determinada (coisa de positivistas), é quase redundância

\footnotetext{
* Conforme já ficou referido, Perry Anderson chama de ecletismo teórico esse traço do marxismo ocidental que consiste em fazer empréstimos teóricos com o aparente objetivo de "enriquecer o pensamento marxista". Este é um bom exemplo, pois se trata de empréstimo tomado de Bachelard. Como não temos condições de avaliar o seu alcance, lembramos apenas que, do ponto de vista financeiro, normalmente quem sai ganhando com um empréstimo é o agiota...
} 
dizer que por essa proposição Lukács acaba recebendo a sua medalhinha de honra ao mérito positivista. Mas Adorno não fica nisso, pois para além dessa discussão ele tem uma proposta - a da teoria (crítica) que não é sistema. Reunindo, então, os dois problemas (arte e ciência, teoria e sistema), apresenta a seguinte resposta a Lukács: "o ensaio é ao mesmo tempo mais aberto e mais fechado do que gostaria o pensamento tradicional. É mais aberto porque nega toda sistemática e se basta tanto mais a si mesmo quanto mais rigorosamente se atém a esta negação (...) E também é mais fechado porque trabaIha enfaticamente na forma da exposição. A consciência da não-identidade entre a exposição e seu objeto impõe um esforço ilimitado à exposição.

É só nisto que o ensaio se aparenta com a arte; no mais seu parentesco se dá com a teoria, por causa dos conceitos que nele aparecem, os quais trazem de fora suas significações e suas referências teóricas (...) Assim como absorve de fora conceitos e experiências, absorve também teorias (...) (Mas) o ensaio consome as teorias que lhe são próximas; sua tendência é sempre a de liquidar a opinião, inclusive a opinião que toma como ponto de partida" (1, p. 29-30). E com essa resposta a Lukács encontramos, nada por acaso, boa parte da explicação de Adorno para a sua escolha metodológica (se ele nos perdoa a heresia): o máximo que seu pensamento anti-sistemático tolera em termos de exposição é a teoria, nunca o sistema.

Através de Paulo Arantes ficamos sabendo que Hegel considerava o ensaio como exemplo de dissertação arbitrária. De fato, na Introdução aos Princípios da Filosofia do Direito, encontramos um ataque aos que reivindicavam os direitos da subjetividade, a devoração de teorias e a exposição comprometida com o objeto: "o modo da consciência imediata e do sentimento transforma a contingência, a subjetividade e o arbitrário em princípios (...) Se este método é o mais cômodo, é também o menos filosófico" (7, p. 49). Sem grande surpresa, encontramos no mesmo lugar a informação de que este método menos filosófico veio substituir o mais ou menos desaparecido método formalista das definições, silogismos e demonstrações... Mas voltemos a Adorno antes que se crie um imbroglio.

A digressão acima é provocada pelo próprio Adorno, uma vez que reivindica o caráter dialético de sua forma. Como são bem conhecidas as objeções que vêm desde Marx ao caráter idealista da dialética hegeliana e os mais recentes reparos à dificuldade que teve Hegel - dificuldade afinal não superada - na tentativa de enquadrar sua dialética em sistema, passemos simplesmente a palavra a Adorno: "o ensaio é mais dialético do que a dialética quando se expõe a si mesma, pois esta continuou falando em 'método' dialético, segundo o costume idealista; o ensaio toma a lógica de Hegel ao pé da letra; (...) para salvar o pensamento da arbitrariedade assumiu-a em seu próprio procedimento, ao invés de mascarar a arbitrariedade, disfarçando-a de imediaticidade" (1, p. 30-31). Isto não pode, em nenhuma hipótese, levar à conclusão (tentadora) de que o ensaio, assumindo a arbitrariedade, não tem lógica. Resumindo o argumento de Adorno, podemos dizer que o ensaio também tem a sua lógica. Está claro que não se trata da velha lógica meramente discursiva ou da nova lógica das exigências matemáticas. Estamos falando da lógica dialética, a que não admite meras contradições que redundariam em inconseqüência; o que se encontra no ensaio são contradições que se fundamentam como contradições da própria coisa. E encerremos este capítulo com as considerações finais de Adorno ampliando o alcance das contradições presentes no ensaio: "a mais íntima lei formal do ensaio é a heresia. Por violência contra a ortodoxia do pensamento se torna visível na coisa aquilo que a ortodoxia tem por finalidade secreta e objetiva manter oculto" (1, p. 36).

\section{A CONSOLAÇÃO DA TRAGÉDIA}

Comentando esse texto de Adorno, em nota e como se fosse mesmo en passant, Paulo Arantes aponta um detalhe fundamental: "Notemos de passagem que Adorno mostra-se 
curiosamente discreto acerca do processo que induz esse tipo de construção formal". De fato, é curioso pois as exigências teóricas do próprio Adorno passam por aí. Ele trata disso inúmeras vezes, mas basta, para exemplificar, a seguinte passagem de sua Teoria Estética: "alguém que não compreende o aspecto puramente musical de uma sinfonia de Beethoven, compreende-a tão pouco como alguém que nela não percebe o eco da Revolução Francesa" (2, p. 383).

Se Adorno foi discreto acerca desse processo social, não seríamos nós a preencher tal lacuna, além do que fez Perry Anderson. Mas não custa puxar pelo menos um fio da meada que vem de Adorno e de Habermas para tentar ligar algumas coisas que ainda estão soltas. Para Adorno, "historicamente o ensaio tem parentesco com a retórica, que a mentalidade científica quis combater, desde Descartes e Bacon, até que, muito conseqüentemente, esta acabou por rebaixar-se, na era científica, à categoria de uma ciência sui generis, a ciência da comunicação. Por certo a retórica desde sempre foi o pensamento adaptado à linguagem comunicativa. Este pensamento apontava para a óbvia e trivial satisfação dos ouvintes. É precisamente na autonomia da exposição, pela qual se diferencia da comunicação científica, que o ensaio conserva restos daquele elemento comunicativo que falta à comunicação científica" (1, p. 32-33). Habermas aponta mais claramente o que subjaz a esta defesa do momento retórico no ensaio: "O ensaio filosófico paga por suas vantagens o preço de ser menos rigoroso, mas essas vantagens, apesar de tudo, são reais, em confronto com as formas mais sistemáticas de apresentação que predominam hoje na Alemanha Federal, sob a influência da filosofia analítica. Graças a seu caráter literário, o ensaio tem acesso mais fácil à consciência pública e, portanto, maior eficácia do ponto de vista publicístico" (6, p.68-69). De modo que tanto Adorno como Habermas, defendendo o retórico, admitem explicitamente a intenção de influenciar um público.

Por esse fio vamos encontrar o que ao mesmo tempo aproxima e afasta o marxismo ocidental do marxismo clássico, assim como um dos elementos daquele processo histórico já referido. Quanto ao marxismo clássico, ao invés de ensaios temos basicamente dois tipos de textos. Os menos freqüentados, os tratados, como $O$ Capital, obras de Lênin, Trotsky, Bukharin, Rosa de Luxemburgo e os mais acessiveis que, à falta de um nome próprio, podemos chamar de textos de intervenção, tais como artigos de jornais e revistas, contribuições em debates, propostas programáticas, etc., que os mesmos autores acima também produziram. Sem qualquer levantamento estatístico, ousaríamos apostar que este segundo tipo de textos predomina na literatura marxista clássica e é com ele que o ensaio dos frankfurtianos reivindica parentesco, se levarmos a sério aquela vantagem apontada por Habermas - o acesso mais fácil à consciência pública e portanto maior eficácia do ponto de vista publicístico: os ensaios da Escola de Frankfurt pretendem ser alguma forma de intervenção. Outra coisa é saber no que pode dar essa intervenção, já que a linguagem altamente especializada destes marxistas não é a menor das barreiras que seu "público visado" tem a superar para chegar a eles. (O uso da expressão típica do jargão publicitário é proposital: como não estamos pretendendo produzir um ensaio, não precisamos seguir a "boa técnica ensaística" que, conforme lembra Paulo Arantes, "recomenda alusões tácitas, nunca explícitas"). A dúvida sobre a "intervenção" decorre daquela situação do marxismo ocidental que vimos com Perry Anderson - sua desvinculação das organizações políticas operárias. Na medida em que o ensaio é escrito para publicação, falta-lhe o elemento essencial ao caráter do texto de intervenção, isto é, o seu modo de divulgação. Como um texto de intervenção visa a resultados práticos concretos (políticos em sentido estrito), podemos lembrar pelo menos dois modos de sua divulgação: circulação imediata e interna à organização com vistas a dar início ou continuidade a um processo de debates que necessariamente terá como resultado uma decisão política, ou publicação em panfletos, manifestos, jornais ou revistas de militância com as funções de propaganda e organização (de acordo com Lênin). Ora, todos sabem que os ensaios dos filósofos de Frankfurt, com exceção de alguns textos de Walter Benjamin, não têm 
esses modos de divulgação, até porque, mesmo que Habermas fale em "maior eficácia do ponto de vista publicístico", nunca esteve nas cogitações dos frankfurtianos "organizar" qualquer tendência política: eles não são políticos, mas filósofos e não escrevem textos políticos, mas ensaios filosóficos que, no dizer de Habermas, no máximo podem comunicar-se com o pensamento político. Mas fica, sem dúvida, a nostalgia da intervenção...

Essa nostalgia do espírito de contradição redesorganizado talvez seja assunto para psicanalistas, não é portanto da nossa competência examiná-la. Mas palpite pode-se dar. Dizíamos que para Adorno o objeto do ensaio é úm conflito detido. Por conflito detido entendemos a conjuntura que se abriu com a série de derrotas sofridas pelo proletariado iniciada na Alemanha em 1918. Derrotas à direita (ascensão do nazismo, Segunda Guerra Mundial) e à esquerda (advento do stalinismo, praticamente levando o marxismo à liquidação) que entretanto não resolveram, no sentido dialético, a contradição fundamental do modo de produção capitalista, também conhecida como luta de classes. Conflito detido porque em 1958, quando Adorno publicou o seu ensaio, principalmente na Alemanha era impossivel pensar em solução revolucionária: a reação comia solta. Não é de admirar que, em tais condições, intelectuais marxistas ponham sob suspeição qualquer perspectiva de militância política, abrigando-se na universidade.

Mas este recuo tem um preço. Sugerido pelas análises que Paulo Arantes faz dos contemporâneos de Hegel e Marx dos seus, faz parte do quadro mais amplo da tragédia. A certa altura, Paulo Arantes diz: "O ensaio como forma e o intelectual moderno têm a mesma idade, de tal sorte que as características estruturais de um espelham-se na indole e nos humores do outro". Já vimos com Adorno a índole do ensaio. Vejamos como Mannheim (dica de Paulo Arantes) alguns humores do intelectual: "O membro da intelligentsia pode mais facilmente mudar seu ponto de vista e está menos rigidamente engajado num lado do conflito, pois ele é capaz de experimentar concomitantemente várias abordagens da mesma coisa (...) O fato de estar exposto a várias facetas da mesma questão, assim como seu acesso mais fácil a outras interpretações da mesma situação, de um lado faz com que o intelectual se reconheça numa área mais ampla de uma sociedade polarizada; mas de outro, essas mesmas condições fazem dele um aliado menos digno de confiança do que alguém cujas escolhas se referem a uma seleção menor das várias facetas sob as quais a realidade se apresenta" $(10$, p. 81). O passo dispensa comentários, mas convenhamos que "estar menos rigidamente engajado num dos lados do conflito" se acomoda bastante bem com examinar de vários ângulos (ou com olhar prismático) um "conflito detido".

É ainda em Mannheim, nos seus ensaios por sinal, que Paulo Arantes colhe os seguintes traços e observações sobre o fenômeno mórbido da intelligentsia no século XIX: exílio doméstico, dandismo, ceticismo de bom tom, bovarismo às avessas, gosto pelo paradoxo, pela acrobacia intelectual e pela gratuidade. Em outras palavras, falta de caráter e de convicções. Porque, tendo o senso refinado para recolher o que for conveniente na avalanche das idéias postas à sua disposição, os intelectuais parecem sempre prontos a dar as boas vindas às idéias novas e, instáveis, também prontos a mudar de idéia tão logo as coisas andem mal ou não satisfaçam suas expectativas abstratas. Embora a transcrição de Mannheim diga respeito à situação da Alemanha no quadro da transição retardatária para o capitalismo (estudado, diga-se de passagem, de "menos ângulo" por Marx em obras como Introdução à Crítica da Filosofia do Direito de Hegel, A Sagrada Familia ou A Ideologia Alemã), o emprego dos verbos no presente não deve ser tomado como equívoco: a idéia é apontar a possibilidade que tais traços voltem a se manifestar em tempos de capitalismo tardio. (É claro que esses humores não se aplicam a Adorno, mas já não temos tanta certeza quanto a seus discípulos). Manifestação acompanhada do mesmo tipo de opções formais - o ensaio é apenas uma delas. É Massimo Cacciari quem apre-

Trans/Form/Ação, São Paulo, 9/10: 41-49, 1986/87. 
senta o ensaio como consolação da tragédia (5, p. 75). Tragédia porque sua proposição tem algo a ver com o momento do ensaio de Adorno em que a retórica entrou em cena: "A satisfação que a retórica quer proporcionar ao ouvinte se sublima no ensaio até se transformar na idéia da felicidade de uma liberdade frente ao objeto" (1, p. 33). Mas se já sabemos que o objeto do ensaio é o conflito detido, não seria o caso de perguntar se não se está repondo a velha ilusão do intelectual sem amarras? Ou, mais especificamente, as ilusões do protagonista da Ideologia Alemã?

COSTA, I. C. - Adorno's essay and the social production of form. Trans/Form/Ação, São Paulo, 9/10: 41-48, 1986/87.

ABSTRACT: In order to discuss essay as a form in its relationship to philosophy, we take Adorno's text, "Essay as form", to investigate this formal choice of Frankfurt School. Once we find Adorno's proposition about the object of essay as a detained conflict, we try to suggest some of the social motivations to this choice.

KEY-WORDS: Classic marxism; western marxism; dialectical method; negative dialectic; critical theory; intelligentsia; political organization.

\section{REFERÊNCIAS BIBLIOGRÁFICAS}

1. ADORNO, T. - El ensayo como forma. In:- Notas de literatura. Barcelona, Ariel, s.d.

2. ADORNO, T. - Teoria Estética. Lisboa, Martins Fontes, 1980.

3. ANDERSON, P. - Consideraçōes sobre o marxismo ocidental. Lisboa, Afrontamento, s/d.

4. ARANTES, P. E. - Origens do espírito de contradição organizado. In:- Manuscrito. Campinas, Unicamp, 1985.

5. CACCIARI, M. - Metropolis. Roma, Officina Edizioni. 1973 (Cap. Ensaio e Tragédia, p. 59-79).

6. HABERMAS, J. - Prefácio ao leitor brasileiro. In: FREITAG, B. \& ROVANETE, S. P., org. - Habermas. São Paulo, Ática, 1980.

7. HEGEL, G. W. F. - Principes de la philosophie du droit. Paris, Gallimard, 1963.

8. LUKÁCS, G. - Sobre la esencia y forma del ensayo. In:-Elalma ylasformas. Barcelona, Grijalbo, 1975.

9. MANDEL, E. - O capitalismo tardio. São Paulo, Abril Cultural, 1982.

10. MANNHEIM, K. - Sociologia da cultura. São Paulo, Perspectiva, 1974. 